\title{
Percepção Emocional e Processamento de Informações Emocionais no Reconhecimento de Expressões Faciais: origens psicológicas do julgamento social
}

Leonardo Ferreira Almada

leonardo.f.almada@gmail.com

Universidade Federal de Uberlândia, Uberlândia, MG, Brasil.

resumo Neste artigo, pretendemos defender a tese segundo a qual julgamentos sociais se iniciam com a percepção emocional e com o processamento de informações emocionais no reconhecimento de expressões faciais. Para tanto, revisaremos modelos que discutem (i) os mecanismos pelos quais as expressões faciais são codificadas para transmitir informações e ser percebidas pelos outros, (ii) os mecanismos perceptivos de decodificação e categorização de expressões faciais, (iii) os mecanismos pelos quais o reconhecimento de expressões faciais geram respostas emocionais e ajustes comportamentais e, por fim, (iv) a eficiência de nosso sistema perceptual na decodificação desses processos. Com essa discussão, nossa intenção é a de (i) explicitar em que sentido nossa percepção emocional de expressões faciais é um dos principais mecanismos evolutivos de regulação da vida e que (ii) o processamento de informações emocionais é um poderoso instrumento para assegurar a sobrevivência e sustentar razoáveis interações sociais.

palavras-chave Percepção emocional; processamento de informações emocionais; expressões faciais; decodificação perceptiva; respostas emocionais; julgamentos sociais e morais

\section{Introdução: Definição do Problema}

Em geral, o surgimento de pesquisas em Neurociência Comportamental e em Neurociência Cognitiva está claramente associado com explícitas motivações filosóficas. Seja no âmbito das discussões dedicadas às estruturas neurais que produzem comportamentos e fenômenos psicológicos como o sono, os comportamentos sexuais e os comportamentos

Recebido em 17 de abril de 2012. Aceito em 03 de setembro de 2012.

doispontos, Curitiba, São Carlos, vol. 9, n. 2, p.33-61, outubro, 2012 


\section{4}

emocionais (Neurociência Comportamental), seja no âmbito das discussões que envolvem nossas capacidades mentais mais complexas, como a linguagem, a autoconsciência, a percepção, e a memória (Neurociência Cognitiva), o que está efetivamente em jogo é a natureza das relações mente-cérebro e a estrutura geral do comportamento ${ }^{1}$.

Dentre os inúmeros problemas filosóficos que fazem parte do conjunto de interesses das Neurociências, a percepção tem ocupado posição de destaque. O milenar interesse filosófico por noções que pressupõem de maneira significativa a percepção - como a natureza da verdade, do erro, do acesso à realidade e às coisas - tem sido assimilado por incontáveis discussões neurocientíficas. A análise neurocientífica da natureza da percepção (interna e/ou externa) e o exame de seu funcionamento em condições normais, alteradas e/ou patológicas estão na base investigativa dos inúmeros transtornos psiquiátricos que se originam em disfunções, exageros ou falsas interpretações das percepções, como, por exemplo: Transtorno do Pânico, Transtorno Dissociativo de Identidade, Transtorno Bipolar, Transtorno Depressivo Maior e a Esquizofrenia, dentre outros (PHILLIPS et. al., 2003a; PHILLIPS et. al., 2003b). Os critérios diagnósticos para grande parte desses transtornos psiquiátricos se fundamentam em uma noção epistemológica (ainda que incipiente) segundo a qual as percepções internas e externas podem ser "verdadeiras", "alteradas" e/ou "erradas”. É, portanto, com base na noção de que as percepções se distinguem em verdadeiras, alteradas/distorcidas e/ou erradas que as chamadas percepções e experiências perceptuais incomuns, alteradas, distorcidas, exageradas ou falsas acabam ocupando um papel de destaque em alguns dos principais sintomas característicos de determinados transtornos psiquiátricos (DSM-IV).

Diferentemente do que está suposto no discurso comum acerca do papel exercido pelas percepções na constituição de certos transtornos psiquiátricos, as alterações, distorções, falhas interpretativas e exageros não dependem exclusivamente de aspectos cognitivos das percepções. Com efeito, do mesmo modo que as percepções podem estar na base de nosso sistema neural cognitivo, as percepções também participam de nossos sistemas neurais emocionais: a investigação sobre a natureza e o funcionamento da percepção pode estar a serviço da análise de nossos processamentos cognitivos ou de nossos processamentos emocionais. 
Interessa-nos, no entanto, a investigação da chamada percepção emocional. Trata-se do interesse que temos de analisar algumas posições e modelos teóricos que se dedicam a demonstrar como tomamos decisões e como realizamos os chamados julgamentos morais e sociais a partir da percepção emocional e do processamento de informações emocionais no reconhecimento de expressões faciais. Com efeito, acreditamos que nosso interesse diz respeito a um dos mais profícuos e produtivos campos de pesquisa no âmbito das interfaces entre Filosofia e Neurociências.

Uma das mais privilegiadas fontes de informação para julgamentos morais e sociais é a nossa percepção emocional do conjunto de sinais/informações transmitido pelo corpo de outros indivíduos. Sinais/informações emocionais nos informam sobre: (i) como os outros avaliam a situação (ou um objeto específico naquela situação); (ii) quais são as intenções comportamentais do sujeito naquele contexto; (iii) a susceptibilidade dos outros aos nossos comportamentos e decisões, e (iv) se os outros acatariam ou se oporiam a nossas decisões comportamentais. A decodificação perceptiva das expressões emocionais alheias é um componente-chave para julgamentos morais e sociais e para muitos processos de decisão, sendo provavelmente o mais importante componente em situações que envolvam ameaças e perigos, reais ou potenciais (MOGG; BRADLEY, 2002).

Essa percepção do conjunto de sinais emocionais transmitidos pelos corpos de outros indivíduos recebe o nome de cognição social. Com efeito, a cognição social tem sido definida como a habilidade que temos de interpretar e predizer os comportamentos, crenças e intenções de outros organismos, de onde resulta a capacidade que temos de interagir em relações e em ambientes sociais complexos. Nesse sentido, tanto a habilidade para decodificar perceptivamente conteúdos e estímulos emocionais presentes no ambiente quanto à capacidade para rememorar e distinguir informações de significação emocional neutra ou alta são partes integrantes da cognição social (KEIGHTLEY et. al., 2007; GOBBINI; HAXBY, 2007).A cognição social se estrutura em variáveis específicas que se destinam à decodificação da emoção nessas situações. Uma das mais relevantes é a diz respeito à percepção emocional no reconhecimento de expressões faciais, que tem recebido atenção particularizada e maciça por parte das Neurociências Cognitiva e Comportamental. 
Com efeito, as faces não se limitam a fornecer meras informações distintivas sobre a identidade, gênero ou idade de uma pessoa. A face humana é um transmissor por excelência de sinais emocionais, e o cérebro (por meio de nosso sistema de percepção visual) é o decodificador desses sinais emocionais. Seja por meio de nossas expressões faciais seja por meio de nossas micro-expressões faciais, a face está envolvida na transmissão de sinais do mesmo modo que nosso sistema de percepção visual é "inatamente" programado para categorizar e interpretar de maneira acurada essas expressões, sem o que provavelmente a espécie humana já estaria extinta (SMITH et. al., 2005).

A capacidade de interpretar acuradamente a significação emocional das expressões faciais é, sem dúvida, um dos principais mecanismos evolutivos de regulação da vida, que herdamos para assegurar a sobrevivência e para sustentar razoáveis interações sociais, não só entre humanos, mas entre grande parte dos animais não humanos. Se é por meio de julgamentos sociais que asseguramos os melhores níveis de interação social, também é verdade que só realizamos julgamos sociais a partir da capacidade de decodificar categorizações emocionais em organismos e em faces alheias. Isso significa que, mesmo não dispondo de mecanismos de acesso privilegiado a outras mentes, podemos inferir rapidamente o estado emocional geral da mente alheia a partir das informações que recebemos das expressões faciais; é a partir dessas informações que podemos realizar respostas corporais preparatórias e ajustes comportamentais apropriados, conscientemente ou não.

É bem verdade, no entanto, que até o momento dispomos de poucas informações sobre como esses vários sinais transmitidos pela face são codificados, integrados e percebidos por uma única face. Sabe-se com alguma convicção que as informações conscientemente processadas respondem por uma ínfima parte de nossa percepção do outro. Afinal, as faces enviam incontáveis sinais sutis e de processamento não consciente, a partir dos quais percebemos o conjunto de emoções experienciadas pelo outro, sua confiabilidade ou inconfiabilidade, sua atratividade ou aversidade assim como a direção do olhar e suas intenções subliminares (VUILLEUMIER; POURTOIS, 2007, p.174).

Nesse sentido, a face pode ser biologicamente considerada como portadora de "estímulos multidimensionais", capaz de receber e de trans- 
portar, simultaneamente, muitos sinais relevantes, cada qual com sua complexidade social e com sua significação motivacional (VUILLEUMIER; POURTOIS, 2007, p.174). Sobre essa característica "multidimensional" dos estímulos enviados pela face, a Neuropsicologia Cognitiva tradicional considerou que processamentos de aspectos diferentes da face envolvem rotas de processamento diferentes, especializadas e paralelas. Esse modelo cognitivo remonta à clássica publicação de Bruce de Young (1986), de acordo com a qual o reconhecimento da identidade de expressões faciais (aspectos invariáveis, conscientes e explícitos das faces) e o reconhecimento da significação emocional de expressões faciais (aspectos variáveis, não conscientes e implícitos das faces) são processados ao longo de dois percursos neurais separados e independentes, assimetricamente interdependentes.

$\mathrm{O}$ recurso às tecnologias de neuroimagem fundamentou grande parte da tese neuropsicológica de Bruce e Young (1986), na medida em que diferentes regiões cerebrais passaram a ser associadas com nossas diferentes habilidades, a saber, a capacidade de perceber identidade facial e a capacidade de percepção emocional de expressões faciais. Nesse sentido, a novidade em relação ao tradicional modelo neuropsicológico consiste no reconhecimento de que regiões corticais distintas - córtex fusiforme e córtex temporal superior - estão respectivamente associados com o reconhecimento dos aspectos invariáveis, conscientes e explícitos das faces e com o reconhecimento dos aspectos variáveis, não conscientes e implícitos das faces (VUILLEUMIER; POURTOIS, 2007, p.175).

Naturalmente, as investigações das Neurociências contemporâneas se atêm mais particularmente às expressões faciais emocionais (os aspectos variáveis, não conscientes e implícitos das faces), na medida em que são incentivos biológicos fundamentais e de grande relevância no comportamento social e, em consequência, no modo como fazemos apreciações e julgamentos sociais. Trata-se, nesse sentido, de uma atenção particularizada aos processos de percepção que exercem mais influência na orientação de trocas interpessoais e no comportamento durante as interações sociais. Além de a face humana ser de grande significação emocional, sabe-se também que dispomos de regiões cerebrais especializadas para processar os sinais emocionais gerados pelas faces. Com efeito, os sinais emocionais percebidos de uma face (sem processamento cognitivo) influenciam de 
maneira significativa o modo como abordamos e depois nos lembramos de uma pessoa desconhecida, assim como influenciam o modo como a familiaridade prévia com alguém influencia a percepção e interpretação das expressões faciais (GOBBINI; HAXBY, 2007; VUILLEUMIER; POURTOIS, 2007, p.175).

Segundo Adolphs (2003), as relações de interação entre experiências emocionais e percepção emocional de expressões faciais é um dos principais caminhos a partir dos quais entendemos a arquitetura das funções sociais do cérebro humano, e é também o que nos fornece importantes insights sobre os mecanismos gerais das relações de interação e integração entre processos cognitivos e processos emocionais ${ }^{2}$.

As pesquisas acerca da percepção emocional no reconhecimento de expressões faciais se iniciaram com o delineamento e categorização universal das expressões faciais, isto é, com a defesa de que expressões faciais independem de fatores culturais. Essa defesa encontrou suas origens mais precisas em Darwin (1872/1965) e, posteriormente, nos trabalhos de Izard $(1971,1994)$ e de Paul Ekman e Friesen $(1975,1978)$, tendo atualmente em Ekman (2003) uma referência importante, ainda que nem de longe seja atualmente a única.

A relevância das pesquisas de Darwin, Izard, Ekman e Friesen diz respeito mais especificamente aos pilares desse campo investigativo, e se deve às seguintes demonstrações: (i) as expressões faciais são universais; (ii) as expressões faciais são resultados observáveis da evolução; (iii) as respostas emocionais (que se expressam no organismo e na face) são reações automáticas e involuntárias geradas por nossa percepção do ambiente, de tal modo que o desejo de experienciar ou não experienciar uma emoção gera comportamentos distintos em relação à vivência espontânea de uma dada emoção; (iv) expressões faciais transmitem sinais eficientes, claros, rápidos e espontâneos, sendo capaz de trazer informações importantes para o outro e de gerar um conhecimento que possibilita a cooperação social. Esses princípios têm norteado, de um modo ou de outro, todas as pesquisas avançadas acerca da percepção emocional e do processamento de informações emocionais no reconhecimento de expressões faciais. Mais que isso, esses princípios sugerem que a mais relevante implicação dessa investigação diz respeito, direta ou indiretamente, ao problema da cognição social; mais especificamente, ao modo como 
fazemos julgamentos morais e sociais. Com efeito, temos verificado que esses princípios estão na base de grande parte das investigações neuropsicológicas acerca das nossas relações de interação social.

Ademais, esses princípios de base têm possibilitado que diferentes campos do conhecimento se debrucem sobre um relevante grupo de questões: (i) Como as informações faciais são codificadas para transmitir informações e ser percebidas pelo outro?; (ii) Como as informações são decodificadas por nosso sistema perceptivo para categorizar expressões faciais e preparar respostas corporais e ajustes comportamentais?; (iii) Quão eficiente é nosso sistema perceptual na decodificação desse processo?

Nesse artigo, queremos propor a ideia de que nossos julgamentos sociais têm origens bem definidas na percepção emocional e no processamento de informações emocionais de expressões faciais. Com isso, propomos também demonstrar que a significação filosófica das investigações sobre a percepção emocional e o processamento de informações emocionais no reconhecimento de expressões faciais consiste na capacidade que temos de discernir importantes componentes de nossas relações ético-sociais.

\section{Percepção Emocional de Estímulos com Significação Emocional}

A investigação acerca de como a percepção emocional e o processamento de informações emocionais no reconhecimento de expressões faciais fundamentam juízos sociais e morais traz consigo duas dificuldades interrelacionadas e indistinguíveis, a saber, (i) a heterogeneidade dos fenômenos que podemos chamar de emoções, e o fato de que, apesar de fazerem parte de um ciclo fortemente coeso, (ii) emoções e sentimentos são processos completamente distintos (DAMASIO, 2010). A controversa distinção entre emoções e sentimentos remonta a William James (1884), para quem não é correto distinguir emoções de sentimentos, na medida em que as emoções são o próprio sentimento das mudanças corporais durante a percepção de um fato excitativo. Nesse sentido, não há distinção fisiológica e conceitual significativa entre emoções e sentimentos. A sinonimização estabelecida por James tem sido alvo de muitas críticas, especialmente de Damasio (2010), para quem emoções e sentimen- 
tos são processes claramente distintos, a saber, emoções constituem estados mentais que envolvem ideias e certos modos de pensar, enquanto que sentimentos emocionais são as percepções daquilo que nosso corpo faz durante a emoção.

Emoções são programas de ações complexos e em grande medida automatizados, engendrados pela evolução. Essas ações complexas são complementadas por um programa cognitivo que inclui ideias e modos de cognição. O mundo das emoções depende de ações que são executadas no corpo, o que inclui desde expressões faciais e posturas até mudanças nas vísceras e no meio interno (DAMASIO, 2010). Por outro lado, sentimentos emocionais podem ser considerados como percepções daquilo que ocorre em nosso corpo e em nossa vida mental ao longo do curso de uma emoção. Ademais, em nosso corpo, os sentimentos se expressam como imagens de ações e não ações propriamente ditas. $\mathrm{O}$ mundo dos sentimentos consiste de percepções executadas em mapas cerebrais, e sentimentos se baseiam em uma relação única entre o corpo e o cérebro, com a intenção de privilegiar a interocepção ou propriocepção.

Emoções e sentimentos não são expressões faciais, mas estados mentais. Como podemos então explicar certa "capacidade" de "perceber" ou de "detectar emocionalmente" as emoções e sentimentos alheios? À primeira vista, a resposta para essa questão é simples: por meio de nossas teorias da relação mente-cérebro, e com o auxílio dos recentes recursos de neuroimagem, aprendemos que (i) a atividade cerebral gera estados mentais que chamamos de emoções; que (ii) as emoções ou se seguem ou são acompanhadas ou geram comportamentos específicos (expressões corporais) que chamamos de sentimentos, e que (iii) temos mecanismos biológicos pelos quais somos capazes de reconhecer esses comportamentos específicos (expressões corporais), em nós e nos outros (ZAMUNER, 2011).

Por meio de nossos mecanismos de processamento perceptivo, e em face dos comportamentos específicos (expressões corporais) de nossos e de outros organismos, apreendemos informações/sinais emocionais de maneira explícita, ou seja, a partir de processamentos perceptivos conscientes que geram atividades deliberativas. Por outro lado, a evolução também nos dotou da capacidade de reconhecer informações/sinais emocionais de maneira implícita, involuntária e sem controle consciente, o que significa, de maneira automática, sem intervenção significativa ou 
simplesmente sem intervenção de nossos processos atencionais e cognitivos. Por fim, o reconhecimento de informações/sinais emocionais pode ocorrer a partir de uma maneira mista, sem delimitações claras entre a deliberação e o automatismo, entre a percepção explícita e a implícita, entre a voluntária e a involuntária, ou seja, de modo que não saibamos distinguir percepção consciente de não consciente. Seja por meio das formas de percepção completamente automáticas, seja por meio das formas parcialmente automáticas, é apenas por meio da capacidade de apreendermos informações/sinais emocionais de maneira implícita, involuntária e não consciente que conseguimos agir rapidamente em situações reais ou potenciais de perigo e ameaça. Em termos mais simples, mecanismos básicos de sobrevivência não costumam envolver processos deliberativos, mas respostas corporais e ajustes comportamentais involuntários e automáticos (TAMIETTO; GELDER, 2010).

Sobre a capacidade perceptiva que temos de assimilar informações ou sinais oriundos de organismos alheios, Zamuner (2011) advoga a polêmica e, segundo julgamos, insustentável ideia segundo a qual nossa percepção visual é capaz de apreender o próprio estado afetivo de outra pessoa, e não apenas seu comportamento. Trata-se da ideia de que o estado emocional de outra pessoa está disponível no estímulo que chega a nossos olhos, e que nossa percepção visual tem por função primordial a capacidade de extrair a essência dessa informação. Deduzimos que a posição de Zamuner, além de incorrer no risco de se comprometer com uma controversa defesa da possibilidade de acessar estados mentais de outras pessoas, ainda pode dar margem à equívoca ideia de que nossa percepção visual sempre trabalha em um nível consciente. Não é nossa proposta discutir a posição de Zamuner (2011) em profundidade, mas podemos dizer que, se nossas suspeitas se confirmam, essa perspectiva é inaceitável, e com razão não tem sido assimilada por nenhuma abordagem neuropsicológica atual.

Com efeito, as perspectivas que presumem a possibilidade de acesso a estados mentais de outras pessoais se comprometem com teses ainda mais controversas do que as noções de "introspecção" e de "acesso privilegiado". Ora, se ainda não dispomos de evidências significativas em favor da ideia de que podemos ter acesso a nossos próprios estados mentais, ou seja, se as defesas da "introspecção" e do "acesso privilegiado" têm se 
sustentado em bases argumentativas e empíricas tão frágeis, como podemos tentar defender uma possibilidade ainda mais inimaginável, qual seja, a de que podemos ter a capacidade de acessar outras mentes? Ora, não é por acaso que o problema das outras mentes, quanto equacionado de maneira correta, tem sido uma das mais complexas e insolúveis questões contemporâneas da Filosofia da Mente.

Praticamente todas as pesquisas existentes sobre a capacidade perceptiva que temos de assimilar informações/sinais emocionais oriundos de organismos alheios partem de uma posição contrária em relação à tese de Zamuner (2011), ou seja, da ideia de que não dispomos de recursos argumentativos e tampouco empíricos para sustentar a possibilidade de acesso a estados mentais dos outros. Nesse sentido, a maneira aparentemente mais infrutífera de analisar como assimilamos informações emocionais de outros organismos consiste em tentar delinear caminhos de acesso aos estados emocionais de outras mentes. Por outro lado, porém, parece bastante frutífera a estratégia investigativa a qual se propõe examinar a natureza da percepção emocional e dos mecanismos de processamento emocional pelas quais apreendemos estímulos emocionalmente significantes, conscientes e não conscientes. Daí porque restringimos nosso interesse às seguintes questões: O que é uma percepção emocional? Quais processos neuropsicológicos subsidiam uma percepção emocional? Como podemos ter percepções emocionais de estímulos emocionalmente significantes? Como processamos informações emocionais no reconhecimento de expressões faciais? Como estruturamos relações sociais com base em nossas percepções emocionais?

Com base em pesquisas experimentais, e por meio de seis teses gerais acerca da natureza da percepção em processamentos cognitivos conscientes e em processamentos emocionais não necessariamente conscientes, LeDoux (1996, p. 69-70) defendeu uma influente concepção sobre como avaliamos e identificamos a significação emocional de estímulos com significativa valência emocional: (i) "podemos perder a capacidade de apreciar a significação emocional de certos estímulos sem nenhuma perda da capacidade de perceber esses estímulos como objetos”. Essa primeira tese, que estabelece uma distinção entre componentes cognitivos e emocionais da percepção, se refere aos casos em que nossa capacidade de percepção emocional (automática e independente de 
mecanismos avaliativos) é prejudicada em função de lesões ou disfunções cerebrais, sem que isso implique prejuízo para nossa percepção consciente e cognitiva; (ii) "O significado emocional dos estímulos pode começar a ser apreciado pelo cérebro antes do sistema perceptual ter processado totalmente o estímulo. É realmente possível ao cérebro saber se alguma coisa é boa ou má antes de saber exatamente o que é”. A segunda tese é consequência da primeira, e se propõe evidenciar a capacidade que temos de realizar percepções emocionais sem consciência e sem cognição. Nesse sentido, se refere à capacidade perceptiva que temos de apreender sinais emocionais sem processamento consciente; (iii) "Os mecanismos do cérebro através dos quais as memórias da significação emocional dos estímulos são registradas, armazenadas e recuperadas são diferentes dos mecanismos através dos quais as memórias cognitivas dos mesmos estímulos são processadas". Em continuidade com a anterior, essa terceira tese demonstra que os processos perceptivos que fundamentam memórias emocionais não se confundem com os processos perceptivos que engendram memórias cognitivas; (iv) "Os sistemas que realizam apreciações emocionais são diretamente conectados com os sistemas envolvidos no controle das respostas emocionais. Uma vez a apreciação sendo realizada por esses sistemas, as respostas ocorrem automaticamente. Em contrapartida, sistemas envolvidos em processos cognitivos não são hermeticamente acoplados com o sistema de controle de resposta". Essa quarta tese sustenta que a conexão direta entre apreciações emocionais e sistemas de controle de respostas emocionais ocorre de maneira não consciente (automática), diferentemente do que ocorre com a cognição, cuja conexão com o sistema de controle de resposta não é direta, já que implica deliberação; (v) "a ativação dos mecanismos de apreciação estreita as opções de resposta para as poucas escolhas que a evolução sabiamente nos forneceu para conexão com um específico mecanismo de apreciação”. A quinta tese depende da quarta, e estabelece que, por meio de nossos mecanismos de apreciação emocional, a nossa possibilidade inicial de "escolhas" é reduzida para o menor número possível de "escolhas", a saber, apenas as "escolhas" que o organismo considera úteis para assegurar a manutenção de níveis ótimos de homeostasia. Naturalmente, esse processo de redução não envolve processos deliberativos; por fim, (vi) “A ligação dos mecanismos de apreciação com os sistemas de controle de 
resposta significa que os mecanismos de apreciação detectam um evento significativo, sua programação e até mesmo a execução de um ajuste de repostas apropriadas que ocorrerão. As sensações corporais usualmente acompanham apreciações e, quando acontecem, são apenas uma parte da experiência consciente das emoções". A sexta tese estabelece que grande parte de nossas respostas emocionais e de nossos processos de autorregulação emocional envolvem as sensações corporais necessárias para nossas apreciações, e que apenas uma parte dessa relação chega à consciência.

Em consonância com a estrutura geral das teses centrais de LeDoux (1996), Phillips e colaboradores (2003a, p. 504) se estabelecem em uma ideia de percepção emocional também fundamentada na ideia de que a apresentação de um estímulo gera, respectivamente, (i) apreciação automática e não consciente da significação emocional de um estímulo (teses (i) e (ii) de LeDoux), (ii) produção de estado afetivo em resposta à apresentação dos estímulos (teses (iv), (v) e (vi) de LeDoux) e (iii) mecanismos de regulação desse estado afetivo (tese (vi) de LeDoux).

Para ser mais preciso, Philips e seus colegas (2003a, p. 504) dividem o processo neuropsicofisiológico básico da percepção emocional nas seguintes etapas: (i) identificação e categorização da significação emocional de um estímulo; (ii) produção de um estado afetivo em resposta ao estímulo emocionalmente competente: incluem-se aí não conscientes respostas autonômicas, neuroendócrinas e somático-motoras (gestos faciais, voz, comportamentos corporais), assim como sentimentos emocionais conscientes; (iii) regulação do estado afetivo e do comportamento emocional, o que pode envolver uma inibição ou modulação dos processos (i) e (ii) e a consequente contextualização de estados afetivos e comportamentos.

As respostas corporais não conscientes e os sentimentos conscientes que resultam da percepção emocional do ambiente constituem mecanismos distintos e assimetricamente dependentes. Essa conjunção de mecanismos conscientes e não conscientes que compõe a percepção emocional é um dos resultados evolutivos mais expressivos da habilidade humana para identificar e categorizar rapidamente uma informação de grande valência emocional, especialmente os estímulos que indicam perigo ou atratividade. Nesse sentido, a percepção emocional pode ser concebida como uma faculdade dependente de atividades neurais, especial- 
mente neuro-hormonais e neuroendócrinas (nesse sentido, não apenas cerebrais), especializadas para detecção e avaliação rápida e eficiente para estímulos com valência emocional neutra e para estímulos com alta valência emocional. Por meio de processos não conscientes, os primeiros são subestimados e os segundos são superestimados (PHELPS; ANDERSON, 2001). Essa rápida identificação e avaliação de estímulos com valência emocional positiva ou negativa têm exclusivamente uma função biológica e não propriamente deliberativa, a saber, gerar respostas corporais e ajustes comportamentais rápidos e apropriados (DARWIN, 1872/1965). Porém, mais do que estar na base das respostas corporais e ajustes comportamentais rápidos, involuntários, não conscientes, automáticos e eficientes, a percepção emocional é também um conjunto de mecanismo sem o qual não seria possível a geração de estados afetivos complexos, experiências emocionais (sentimentos) e comportamentos, conscientes e não conscientes (PHILLIPS, 2003a, p. 504).

Muitas pesquisas têm se dedicado a determinar quais são as regiões neurais que geram respostas automáticas e sentimentos conscientes, visando, assim, a dar conta da estrutura neuropsicológica e da estrutura funcional dos processos de (i) identificação e categorização da significação emocional de um estímulo e de (ii) produção de um estado afetivo em resposta ao estímulo emocionalmente competente. Outros incontáveis estudos têm se dedicado mais especificamente à análise das regiões predominantemente relacionadas com o processo de avaliação da significação emocional de um estímulo com valência emocional, com ênfase no órgão cerebral responsável pela resposta inicial ao estímulo emocionalmente competente, a amígdala 3 (PHILLIPS, 2003a, p. 505).

Em geral, essas pesquisas demonstram que o significativo aumento do fluxo sanguíneo e a consequente ativação da amígdala é uma resposta perceptiva usual (i) a faces não familiares, (ii) à detecção de olhar; (iii) a apresentações de expressões faciais de medo, tristeza, alegria e outras emoções significativas, e mesmo (iv) a cenas de filmes com alto conteúdo emocional. A revisão de Phillips e de seus colaboradores se refere ainda a pesquisas que associam estreitamente a amígdala (v) à percepção visual de palavras ameaçadoras, (vi) a vocalizações de medo, (vii) a estímulos olfativos e gustativos não agradáveis e (viii) à formação de memórias com significativas informações emocionais. Outras pesquisas 
também demonstram a habituação das respostas amigdalares a indicadores visuais que contêm significativas informações emocionais, na medida em que a capacidade de aprender quais estímulos emocionalmente competentes são efetivamente ameaçadores também faz parte de nossos mecanismos de regulação biológica da vida (PHILLIPS, 2003a, p. 505).

Esses achados têm sido corroborados há algum tempo, na figura de pesquisadores que têm demonstrado a participação efetiva da amígdala na modulação perceptiva da vigilância e atenção a estímulos emocionalmente competentes, no condicionamento de medo e mesmo durante a antecipação de estímulos aversivos. Tais demonstrações corroboram a ideia básica de que nossa percepção emocional, por meio de nosso sistema visual, privilegia estímulos com valência emocional positiva ou negativa em relação a estímulos emocionalmente neutros (PHILLIPS et. al., 2003a; LEDOUX, 1996; WHALEN et. al., 2001a; WHALEN et. al., 2001b; WHALEN et. al., 2001c).

Esse conjunto de pesquisas neurocientíficas é consensual quanto ao papel do complexo amigdaloide na fenomenologia emocional, isto é, na determinação de uma experiência emocional. Por outro lado, porém, a dificuldade nas pesquisas dedicadas à percepção emocional e ao processamento de informações emocionais de estímulos com significação emocional se deve ao fato de que a emoção não é um processo mental simples e unitário; uma emoção envolve incontáveis componentes oriundos de eventos neurocognitivos e psicofisiológicos. Daí a dificuldade de definir se a atividade da amígdala representa a geração da experiência emocional em si ou se apenas reflete os variados aspectos do processamento de informação emocional que se correlacionam com a experiência emocional.

Essa dificuldade é provavelmente devida ao fato de que nem sempre as discussões neurocientíficas se propõem estabelecer um conceito mais preciso de consciência, emoção e sentimento, sendo mais usuais as descrições gerais e fundadas nos mecanismos neuropsicofisiológicos dessas noções. Essa característica metodológica justifica a razão pela qual as pesquisas têm girado em torno das relações entre respostas amigdalares e nossa propensão para (i) experiência emocional, (ii) codificação perceptual e (iii) interações emocionais e sociais. É bem conhecido, nesse sentido, que o papel crucial da amígdala no sentimento de uma emoção está 
fortemente vinculado ao aprimoramento da sensibilidade em relação à percepção emocional e à cognição social (BARRETT; NIEDENTHAL, 2004). Por meio de uma amostragem experimental, Barret e Niedenthal (2004) investigaram a ativação da amígdala e a relacionaram com a experiência emocional. Nesse experimento, que visava a medir a decodificação perceptual de eventos emocionais, os pacientes foram apresentados a expressões faciais de medo. $\mathrm{O}$ experimento concluiu que diferenças individuais na propensão para o afeto negativo se devem aos mesmos motivos que justificam uma maior ou menor proeminência das respostas apresentadas a faces de medo. Nos pacientes que experimentaram aumento de ansiedade durante o experimento, respostas amigdalares foram associadas com o aprimoramento perceptual na decodificação de faces a partir do aumento da atividade fusiforme.

Os resultados, portanto, sugerem que a ativação e respostas amigdalares pontuais são imprescindíveis para a experiência perceptiva emocional. São esses processos neuropsicofisiológicos que definem as pré-condições adequadas para a expressão emocional, sobretudo pelo aumento da atenção e da capacidade de decodificação emocional de eventos, objetos e estímulos emocionais: é por meio da ativação e das respostas amigdalares que eventos, objetos e estímulos recebem sua coloração emocional e subjetiva (BARRETT; NIEDENTHAL, 2004).

A tese de Barrett e Niedenthal (2004) segundo a qual o (i) aumento da atenção e (ii) da capacidade de decodificação emocional de eventos, objetos e estímulos emocionais são as pré-condições adequadas para a expressão emocional é uma variação da tese comumente defendida de que as ativações e respostas amigdalares estão mais diretamente relacionadas com (i) as experiências momentâneas, com (ii) o aprimoramento da atenção e com a (iii) sensibilidade em relação à decodificação dessas experiências.

É por meio da capacidade que a amígdala tem de fazer rápidas e momentâneas apreciações atencionais do ambiente que nossos processos perceptuais são alterados para aprimorar a decodificação de eventos com valência emocional intrínseca. Trata-se, enfim, da capacidade que a amígdala tem de constituir estados emocionais capazes de polarizar e focar nossa percepção e atenção para eventos associados com arousal (ativação psicológica) subjetivos e fisiológicos. Lesões amigdalares podem eliminar ou diminuir a polarização subjetiva da percepção no que diz respeito aos 
estímulos emocionalmente significativos. É nesse sentido que (i) grande parte de nossos conteúdos conscientes é modulado por nossas percepções emocionais não conscientes e que (ii) a integridade da modulação de percepções e de estados emocionais depende da integridade da amígdala (ativação e respostas amigdalares).

Em geral, as pesquisas acerca do papel desempenhado pela amígdala na estruturação de nossa percepção emocional tendem a defender que estados emocionais são largamente correlacionados com o modo como pensamos e percebemos o ambiente (BARRETT; NIEDENTHAL, 2004). Essa é a posição de Barrett e Niedenthal (2004), os quais chegam a resultados muito condizentes com nossa intenção nessa seção: experiências emocionais e diferenças individuais podem depender de maneira significativa do modo como percebemos o mundo. Relações sociais dependem do modo como estruturamos experiências emocionais a partir da discriminação de diferenças individuais e, nesse sentido, julgamentos sociais e relações sociais se estruturam no modo como percebemos o mundo. Com efeito, a percepção emocional dos eventos, objetos e estímulos não é uma alteração acessória de nossos processos perceptivos: mais que isso, é uma parcela da experiência emocional em si mesma. Nesse mesmo sentido, a percepção emocional é a base de nossos julgamentos morais e sociais, isto é, de nossa cognição social.

\section{Percepção Emocional e Processamento de Informações Emocionais no Reconhecimento de Expressões Faciais}

Bueno e Primi (2003, p.279-280), concebem o processamento de informações emocionais como um sistema que se subdivide em quatro níveis, organizados em função da complexidade dos processos psicobiológicos envolvidos, a saber, (i) percepção, avaliação e expressão da emoção; (ii) emoção como facilitadora do pensamento; (iii) compreensão e análise de emoções, bem como o subsequente emprego do "conhecimento" emocional e (iv) "controle" reflexivo das emoções.

O primeiro nível (percepção, avaliação e expressão da emoção) inclui a (1) capacidade de identificar emoções em nós, em outras pessoas, em objetos e em condições físicas, a (2) capacidade de avaliar a autenticidade 
de uma expressão emocional, a partir da detecção de sua validade, falsidade ou tentativas de manipulação e a (3) capacidade de expressar essas emoções e as necessidades a elas relacionadas. O segundo nível (emoção como facilitadora do ato de pensar) se refere ao papel desempenhado pela emoção enquanto sistema de alerta e à capacidade que as emoções têm de direcionar nossa atenção e pensamentos para as informações internas e/ou externas mais relevantes do ponto de vista da nossa necessidade biológica de assegurar níveis ótimos em nossa faixa homeostática. O terceiro nível (compreensão e análise de emoções, ou seja, o "conhecimento" emocional) inclui (a) a capacidade que temos de rotular emoções, (b) a capacidade de identificar diferenças e nuances entre as emoções, (c) a capacidade de compreender a possibilidade de sentimentos complexos (por exemplo, amar e odiar a mesma pessoa ao mesmo tempo) e (d) a capacidade de compreender as transições entre os sentimentos (por exemplo, um percurso emocional que leva a pessoa da raiva à vergonha). Por fim, o quarto nível ("controle" reflexivo das emoções) diz respeito à capacidade que temos de (a) tolerar reações emocionais (agradáveis e desagradáveis), (b) compreender reações emocionais sem exagerar ou diminuir sua relevância e (c) controlar ou descarregar nossas reações no momento apropriado.

O modelo de processamento de informações emocionais defendido por Bueno e Primi (2003) parece bem plausível, e concorda essencialmente com grande parte dos modelos fundamentados a partir de investigações empíricas em geral. Por essa razão, esse modelo se constituiu como um satisfatório framework para as pesquisas dedicadas a uma das mais efetivas formas de processar informações emocionais: a apreensão de informações/sinais emocionais das expressões faciais por meio de nossa capacidade de percepção emocional e de processamento de informações emocionais. Como já dissemos em nossa introdução, a percepção emocional e o processamento de informações emocionais no reconhecimento de expressões faciais podem ser considerados como um dos mais relevantes mecanismos de cognição social. Se na seção anterior, referimonos à constituição da percepção emocional em geral, nessa última seção nossa análise recairá mais especificamente, ainda que de maneira breve, sobre a percepção emocional envolvida no reconhecimento de expressões faciais: afinal, o reconhecimento da significação emocional de expressões 
faciais parece ser não apenas o primeiro estágio, mas também o mecanismo mais influente para realização de julgamentos morais e sociais.

Com efeito, as informações e sinais emocionais que assimilamos de outros organismos provêm de comportamentos não verbais, de informações comportamentais em geral e especialmente de expressões faciais. Todorov e Olson (2008) propõem que na verdade precisamos de pouquíssimas informações e sinais para formar alguma impressão sobre outras pessoas. Por exemplo, não precisamos ter conhecimento prévio de outras pessoas para que, a partir de seus traços emocionais mais significativos, elaboremos percepções emocionais e processamentos de informação emocional, algumas vezes (no caso das expressões faciais) de maneira rápida, eficiente e não consciente. É, com efeito, por meio desses processos perceptivos que obtemos informações importantes sobre essa pessoa, pelo menos sobre sua "confiabilidade" ou "inconfiabilidade".

Os processos pelos quais obtemos informações emocionais de uma pessoa a partir de suas expressões faciais e a partir de seu comportamento em geral têm estruturas diferentes. A percepção emocional e o processamento de informações emocionais de faces são muito mais eficientes do que a assimilação de conteúdos com significação emocional oriundos do comportamento. Para atingirmos informações sobre uma pessoa a partir de seu comportamento, é necessário que façamos associações entre as implicações afetivas desse comportamento com a pessoa que executa esse comportamento (TODOROV; OLSON, 2008). Diferentemente de comportamentos, faces são imediatamente categorizadas, especialmente em função de critérios de confiabilidade e inconfiabilidade, ou seja, em função da atratividade intrínseca e/ou da aversividade intrínseca de uma face. Não à toa, faces inconfiáveis geram muito mais ativação no complexo amigdaloide do que faces confiáveis, assim como lesões bilaterais da amígdala (o órgão-chave do processamento emocional) estão associadas com prejuízos na capacidade de distinguir faces confiáveis de faces inconfiáveis (TODOROV; OLSON, 2008).

Nesse sentido, nossa percepção emocional no reconhecimento de expressões faciais não é tão dependente da habilidade mais sofisticada de aprender associações e de ter rememorações emocionais dessas associações. A simplicidade da percepção emocional e do processamento de informações emocionais das faces é o que faz com que o reconhecimen- 
to emocional das expressões faciais seja um dos estágios mais relevantes de nossos julgamentos sociais implícitos de outras pessoas.

Com efeito, estudos com tecnologias de neuroimagem têm indicado que o processamento perceptivo de expressões faciais é modulado pela significação afetiva inerente ao reconhecimento das faces (VUILLEUMIER; POURTOIS, 2007). Essa tese sugere, segundoVuilleumier e Pourtois (2007), que nossos processamentos perceptivos de expressões faciais são modulados por significativas relações de interação e integração entre processos cognitivos e processos emocionais. Mais que isso, a percepção e a cognição são significativamente moduladas por nossas emoções. Daí porque Vuilleumier e Pourtois (2007) fazem parte do grupo que defende a noção de que o processamento de informações emocionais no reconhecimento de expressões faciais está na base de nossos mais simples e também de nossos mais sofisticados mecanismos de cognição social.

Há algum tempo, estudos com instrumentos de neuroimagem têm revelado que a percepção emocional no reconhecimento da significação emocional de expressões faciais é modulada por importantes regiões cerebrais. Em importantes publicações sobre o assunto, Vuilleumier e Pourtois (2007), Adolphs (2003) e Adolphs e Tranel (2003) destacam a existência de uma diferença psicocomportamental entre a ação de (i) construir representações perceptuais detalhadas da face (configurações estruturais e estáticas, mudanças dinâmicas entre suas características) e a ação de (ii) vincular a percepção do rosto com a recuperação de algum conhecimento sobre sua significação emocional e social.

A essa diferença psicocomportamental corresponde uma distinção neurológica específica, a saber, enquanto o córtex temporal superior e o córtex fusiforme participam mais primariamente na ação (i), a amígdala tem participação mais ativa na ação (ii). Os mesmos achados têm sido divulgados por Suslow e colaboradores (2006), que demonstraram, com apoio em exames de neuroimagem (fMRI), ativação ampla (bilateral) da amígdala durante a visualização de faces amedrontadas, e ativação unilateral da amígdala (amígdala direita) durante a visualização de expressões faciais enfurecidas. Como dissemos na seção anterior a propósito de nossa análise da percepção emocional em geral, a ocorrência dessa modulação não é voluntariamente controlada e em grande parte depende de conexões diretas da amígdala com muitas outras regiões cerebrais 
(LEDOUX, 1996; WHALEN et. al., 2001a; WHALEN et. al., 2001b; WHALEN et. al., 2001c).

Esses achados estão na base da tese geral defendida em um estudo clássico de Adolphs, Tranel e Damasio (1998), segundo a qual os julgamentos sociais de outros indivíduos são dependentes da percepção emocional e do processamento de informações emocionais de suas expressões faciais. Parece estar aí a grande significação filosófica das investigações sobre percepção emocional e processamento de informações emocionais no reconhecimento de expressões faciais: a ideia de que estabelecemos julgamentos sociais com base em nossa percepção emocional de expressões faciais.

A tese de Adolphs, Tranel e Damasio (1998) se funda na interpretação de que a amígdala parece ser necessária para recuperar informações emocionais com base em experiências sociais prévias ou com base em nossa tendência pré-programada ("inata") de categorizar certas classes de expressões faciais. Nesse sentido, a amígdala desempenha papel-chave para nosso julgamento social de faces a partir de sua classificação em faces confiáveis e inconfiáveis, o que está de acordo com as demonstrações de que a amígdala processa adequadamente estímulos considerados ameaçadores ou aversivos. A despeito de um conhecimento já estabelecido quanto à participação da amígdala em nossas percepções emocionais de expressões faciais e, em consequência, em nossos julgamentos sociais com base em nossas percepções faciais, é ainda dificil distinguir precisamente a participação de nosso sistema perceptivo nas informações préprogramadas e nas informações que são adquiridas pela experiência individual no âmbito de uma configuração cultural (ADOLPHS;TRANEL; DAMASIO, 1998).

Na mesma linha Adolphs, Tranel e Damasio (1998), Singer e colaboradores (2004) chegaram a resultados que têm sido continuamente corroborados por novas pesquisas com neuroimagens: (i) nosso aprendizado rápido em relação a padrões de status moral das faces alheias envolve as mesmas alterações neurais associadas com a cognição social; (ii) julgamentos sociais de aspectos relevantes da face humana estão na base de nossa percepção emocional de contextos socialmente significativos. Daí porque estudos com neuroimagem funcional envolvendo a recepção da amígdala a estímulos emocionalmente e socialmente significativos têm 
gerado evidências para investigações sobre a cognição social, tanto para julgamentos sociais implícitos quanto para julgamentos sociais que envolvem deliberação.

Com efeito, a amígdala é uns dos órgãos primários e de mais relevância no processamento de emoções e, por conseguinte, em nosso comportamento social, e é por essa razão que qualquer pesquisa acerca dos processamentos emocionais e da percepção emocional no reconhecimento de expressões faciais é tão dependente da amígdala. A capacidade que a amígdala tem de gerar imediatas respostas emocionais e ajustes comportamentais a estímulos visuais representa a capacidade que a amígdala tem de oferecer relevantes informações emocionais e sociais aos estímulos do meio. Com efeito, enquanto os córtices sensoriais estão envolvidos na representação perceptual dos estímulos e de suas características constituintes, a amígdala (junto com o estriato e com o córtex orbitofrontal) media a associação dessas representações perceptuais com respostas emocionais, processamento cognitivo e motivação comportamental. Após essa mediação, as informações são transmitidas para regiões corticais superiores, que estão envolvidas na construção de um modelo interno para o ambiente social, o que envolve representações de outras pessoas, suas relações sociais e o valor da ação individual no contexto se um grupo social (ADOLPHS, 2003).

Nesse sentido, signos visuais sociais, que incluem informações sobre a face, sobre a postura do corpo e sobre o movimento encontram em regiões cerebrais específicas uma rede especializada para perceber e processar informações sobre a significação emocional dessas informações, o que propicia uma surpreendente habilidade evolutiva para realizar julgamentos sociais a partir de informações sociais significativas (ADOLPHS, 2003). Curioso notar que as mais influentes dessas informações provêm de estímulos "pobres", como imperceptíveis mudanças nas expressões faciais ou poucos segundos de interação interpessoal envolvendo o corpo como um todo (ADOLPHS, 2003). Somos, portanto, dotados então de estruturas cerebrais - com amplo destaque à amígdala - que nos torna extremamente sensíveis e receptivos a signos sociais, inclusive os mais sutis. Enfim, nossos processos de percepção emocional e nossos processamentos de informações emocionais abarcam detalhes sociais do contexto nos quais eles ocorrem. 
Daí porque nosso comportamento e nossos julgamentos sociais passam pelas conexões eferentes e aferentes do complexo amigdaloide. Essa é também a razão pela qual as conexões envolvendo o córtex e a amígdala têm sido tão estreitamente associadas com a regulação de nossos comportamentos emocionais e sociais: não por acaso, lesões no complexo amigdaloide prejudicam nossa capacidade de apreciação do significado emocional e social dos estímulos visuais, particularmente a percepção emocional do rosto e a recuperação de algum conhecimento sobre sua significação emocional e social. Em outros termos, esses achados reforçam as teses, defendida há mais ou menos duas décadas, de que (i) a amígdala está estreitamente associada com a percepção de expressões faciais de ameaça e de que (ii) a conexão da amígdala com outras estruturas corticais e subcorticais é o que permite estabelecer respostas a essas ameaças.

Todos esses resultados sugerem que as origens neurobiológicas de nossa percepção da significação emocional de expressões faciais são as mesmas envolvidas em nossa capacidade evolutiva de desenvolver cognição social e de realizar julgamentos sociais. Nesse sentido, tudo indica que a avaliação emocional das expressões faciais esteja fortemente vinculada à capacidade que desenvolvemos de realizar aquelas interações sociais sem as quais a espécie humana provavelmente estaria extinta.

\section{Considerações Finais}

Há algum tempo, temos defendido o princípio metafilosófico segundo o qual a significação de um problema filosófico pouco depende de quem o equacionou, mas da capacidade que o problema tem de ser equacionado filosoficamente. Não se trata de aqui aprofundar as razões de nossa metafilosofia, e tampouco de discutir o que significa "equacionar filosoficamente um problema”, mas de defender que o princípio se aplica ao conceito de percepção. Para além de sua relevância no contexto da história da filosofia, o problema da percepção é também um dos mais caros em inúmeras discussões contemporâneas. Seja quando discutido por filósofos de formação, seja quando discutido por psicólogos ou neurocientistas, o problema da percepção traz consigo uma eminente significação filosófica. 
Com efeito, as discussões neurocientíficas sobre a percepção emocional e sobre os processamentos de informações emocionais no reconhecimento de expressões faciais não se resumem a descrições neuroanatômicas e neurofisiológicas. O que está em jogo é a tentativa de compreender como nós, homens, realizamos complexas relações de interação social, o que quer dizer, quais as bases da cognição social e quais as finalidades de julgamentos sociais e morais. Nesse sentido, não é difícil perceber em que sentido as Neurociências discutem problemas filosóficos.

O processo pelo qual os homens passaram a ajustar os sinais explícitos de nosso comportamento - especialmente de nossas faces - tem sido considerado pelo senso comum como um indicativo de maldade, insinceridade e/ou dissimulação; outros têm considerado essa característica como um indicativo de um processo cultural que está a serviço de relações sociais civilizadas. Talvez não seja correto concordar com a primeira consideração, e talvez possamos concordar parcialmente com a segunda. Parece mais cauteloso e correto defender que nosso aprimoramento da capacidade de ajustar as informações emocionais que passamos aos outros seja basicamente o resultado do reconhecimento - implícito de que específicos contextos sociais necessitam de específicas e correlatas informações emocionais. Trata-se de uma estratégia evolutiva de proteção e de precaução e, nesse sentido, é também um resultado do processo cultural que está a serviço das relações sociais civilizadas. Por outro lado, a evolução também nos dotou da incapacidade de ajustar completamente as informações sociais que transmitimos aos outros: como sabemos, processos emocionais não conscientes alteram - de maneira não consciente, involuntária e não controlada - expressões faciais e comportamentos, e isso também está a serviço da proteção e da precaução dos humanos e de animais não humanos, de uma maneira muito mais eficiente e significativa do que modificações e alterações explícitas, aprendidas, voluntárias e controladas.

Nem de longe esgotamos o assunto com esse nosso primeiro trabalho de revisão teórica sobre o assunto: não fizemos mais do que traçar um breve panorama de alguns modelos e teses que se propõem defender a mesma tese que acreditamos, a saber, a ideia de que nossos julgamentos sociais têm origens bem definidas na percepção emocional e no processamento de informações emocionais de expressões faciais. 
1 Por comportamento, refiro-me especialmente à noção do etólogo Eibesfeldt (1970), para quem comportamento consiste de "padrões no tempo", que podem ser formados por movimentos, vocalizações ou mudanças de aparência. A consideração da noção de "padrões no tempo" na constituição do conceito de comportamento abre espaço para que incluamos, entre os atos comportamentais, os atos de pensamento. Afinal, já que o pensamento corresponde a mudanças na atividade elétrica e bioquímica do cérebro, o ato de pensar também forma padrões no tempo. Podemos entender comportamento também de uma maneira mais simples, no caso, como qualquer tipo de movimento em um organismo vivo. Ainda que todos os seres vivos tenham comportamentos herdados e comportamentos adquiridos ou aprendidos, a complexidade de comportamento varia de espécie para espécie, dependendo, é claro, da complexidade do sistema nervoso. A complexidade do sistema nervoso não significa a exclusão das estruturas neurais mais simples. Pelo contrário, a complexidade do sistema nervoso emerge das novas estruturas, adquiridas evolutivamente, que vão se associando às antigas, isto é, mais primitivas. Nesse sentido, ainda que os humanos possuam o sistema nervoso mais complexo, razão pela qual é a espécie que mais engendra comportamentos aprendidos, é natural que grande parte de seu comportamento remeta a essas estruturas mais antigas e primárias, o que justifica a grande quantidade de respostas herdadas que os homens possuem e compartilham com outros animais, especialmente, mas não exclusivamente, com os primatas.

2 Nas duas últimas décadas, as teorias da emoção têm passado por diversas mudanças em seus elementos nucleares, sobretudo em função dos avanços nas pesquisas empíricas, das constantes reformulações conceituais e de uma série de inovações metodológicas. Dentre tais mudanças estruturais, talvez a mais digna de nota corresponda à significação que passou a se atribuir ao papel das relações entre processos emocionais e processos cognitivos na estruturação do comportamento humano. A despeito da extraordinária significação desta mudança de perspectiva, podemos considerar que ainda é muito recente algum conhecimento mais consolidado acerca das relações dinâmicas de interação e integração entre emoção e cognição. Mais recente ainda é a compreensão, não unânime, de que uma sólida teoria das emoções não prescinde do exame de suas relações com os processos perceptivo-cognitivos. Os postulados que subsidiam tais relações têm sido defendidos por inúmeros neurocientistas, psiquiatras, psicólogos e filósofos. Dentre tantos nomes, vale destacar os esforços de Carroll Izard (2009), que tem sido notável em estabelecer uma teoria da emoção em função de suas relações com a cognição, ação e consciência. Sem dúvida, um de seus grandes méritos consiste em reconhecer que o exame da integração entre emoção e cognição nos leva a uma compreensão mais precisa do papel que os diferentes tipos de emoção têm exercido na evolução, no desenvolvimento dos diferentes níveis de consciência, na mentalidade e no comportamento (IZARD, 2009, p. 2). Minha perspectiva é congruente com a de Carroll Izard. Em comum, sustentamos a ideia de que não é possível negligenciar a interação e integração neural da emoção e cognição (LEWIS, 2005; PESSOA, 2008; PHELPS, 2006), ainda que sejam corretamente tratadas como tendo influências e características funcionais distintas. Estudos polêmicos e recentes têm indicado que os estados emocionais influenciam seletivamente a atividade neural que se relaciona com a cognição no córtex pré-frontal lateral, assim indicando uma forte integração e interação emoção-cognição, fato particularmente rejeitado por parte da tradição filosófica ocidental, e relativizado por inúmeros neurocientistas. Tais estudos, porém, geram grande interesse para o estudo filosófico e científico do comportamento ético, principalmente pelas relações que estabelecem entre raciocínios morais e emoções. Consoante os

doispontos, Curitiba, São Carlos, vol. 9, n. 2, p.33-61, outubro, 2012 
proponentes da pesquisa, emoção e cognição contribuem, de maneira conjunta e igual, para o controle do pensamento e do comportamento: todo comportamento e todo pensamento moral supõe relações intrínsecas entre processos emocionais e processos cognitivos. Indo de encontro a uma série de pesquisas, teorias e modelos que não consideram a integração entre aspectos cognitivos e emocionais, estes pesquisadores recorreram a fMRI para examinar e manipular a conjunção das tarefas cognitivas e dos estados mentais na atividade cerebral, focando especificamente no córtex pré-frontal lateral, "um local em potencial para a integração emoção-cognição". Após o cumprimento das etapas necessárias à pesquisa, os neurocientistas chegaram à seguinte conclusão: "não apenas a emoção contribui para a relação do pensamento e comportamento, mas também a cognição pode contribuir para a regulação da emoção" (GRAY, BRAVER; RAICHLE, 2002, p. 4115-4116).

${ }^{3}$ A amígdala se situa em uma pequena região do prosencéfalo, no interior do sistema límbico, e é um órgão cerebral essencial para vários comportamentos emocionais, com clara independência em relação aos processos conscientes, servindo como ponto de partida para todas as percepções emocionais. É usalmente chamado de órgão de alerta, na medida em que é o primeiro órgão a atuar de maneira significativa em face de estímulos emocionalmente competentes.

\section{Referências bibliográficas}

ADOLPHS, R. 2003. Cognitive Neuroscience of Human Social Behaviour. Nature Reviews Neuroscience, v. 4, n. 3, pp. 165-178.

ADOLPHS, R.;TRANEL, D. 2003. Amygdala Damage Impairs Emotion Recognition from Scenes Only When They Contain Facial Expressions. Neuropsychologia, v. 41, pp. 1281-1289.

ADOLPHS, R.; TRANEL, D.; DAMASIO, A.R. 1998. The Human Amygdala in Social Judgment, v. 399, pp. 470-474.

ANDERSON, A.K.; PHELPS, E.A. 2000. Expression without Recognition: Contributions of the Human Amygdala to Emotional Communication. Psychological Science, v. 11, n. 2, pp. 106-111.

ANDERSON, A.K.; PHELPS, E.A. 2001. Lesions of the Human Amygdala Impair Enhanced Perception of Emotionally Salient Events. Nature, v. 411, pp. 305-309.

ASSOCIAÇÃO PSIQUIÁTRICA AMERICANA (APA). 2002. Manual Diagnóstico e Estatístico de Transtornos Mentais: Revista (DSM-IVTR). $4^{a}$ edição. Porto Alegre, RS: Artmed. 
BARRETT, L.F.; NIEDENTHAL, P. M. 2004.Valence Focus and the Perception of Facial Affect. Emotion, v. 4, n. 3, pp. 266-274.

BRUCE,V.;YOUNG, A. 1986. Understanding Face Recognition. British Journal of Psychology, v. 77, pp. 305-327.

BUENO, J.M.H.; PRIMI, R. Inteligência Emocional: Um Estudo de Validade sobre a Capacidade de Perceber Emoções. Psicologia: Reflexão e Crítica, v. 16, n. 2, pp. 279-291, 2003.

DAMASIO, A. 2010. Self Comes to Mind: Constructing the Conscious Brain. New York:Vintage Books.

DARWIN, C. 1872/1965. The Expression of the Emotions in Man and Animals. Chicago: University of Chicago Press.

EIBESFELDT, I. 1970. Ethology: The Biology of Behavior. London: Holt- Rinehart and Winston Inc.

EKMAN, P. 2003. Emotions Revealed: Recognizing Faces and Feelings to Improve Communication and Emotional Life. New York: Holt Paperbacks.

EKMAN, P.; FRIESEN, W.V. 1975. Unmasking the face. Englewood Cliffs, NJ: Prentice Hall.

EKMAN, P.; FRIESEN, W.V. 1978. The Facial Action Coding System (FACS): A Technique for the Measurement of Facial Action. Palo Alto, CA: Consulting Psychologists Press.

EWBANK, M.P; BARNARD, P.J.; CROUCHER, C.J.; RAMPONI, C.; CALDER, A.J. 2009. The Amygdala Response to Images with Impact. Scan, v.4, pp. 127-133.

GOBBINI, M.I.; HAXBY, J.V. 2007. Neural Systems for Recognition of Familiar Faces. Neuropsychologia, v. 45, pp. 32-41.

GRAY, J.; BRAVER, T.; RAICHLE, M. 2002. Integration of Emotion and Cognition in the Lateral Prefrontal Cortex. PNAS, v. 99, n. 6, pp. 4115-4120. 
IZARD, C. 1971. The Face of Emotion. New York: Appleton-CenturyCrofts.

IZARD, C. 1994. Innate and Universal Facial Expressions: Evidence from Developmental and Cross-cultural Research. Psychological Bulletin, v. 115 , pp. $288-299$.

IZARD, C. 2009. Emotion Theory and Research: Highlights, Unanswered Questions, and Emerging Issues. Annual Review of Psychology, v. 60, pp. 01-25.

KEIGHTLEY, M.L.; CHIEW, K.S.; GORDON, W.; GRADY, C.L. 2007. Age-related Differences in Brain Activity Underlying Identification of Emotional Expressions in Faces. Scan, v. 2, pp. 292-302.

JAMES, W. 1884. What is an Emotion? Mind, v. 19, pp. 188-205.

LEDOUX, J. 1996. The Emotional Brain. New York: Simon \& Schuster.

LEWIS, M. 2005. Bridging Emotion Theory and Neurobiology through Dynamic Systems Modeling. Behavioural and Brain Sciences, v. 28, pp. 169-245.

MOGG, K.; BRADLEY, B.P. 2002. Selective Orienting of Attention to Masked Threat Faces in Social Anxiety. Behaviour Research and Therapy, v. 40, pp. 1403-1414.

PESSOA, L. 2008. On the Relationship between Emotion and Cognition. Nature Reviews Neuroscience, v. 9, pp. 148-158.

PHELPS, E.A. 2006. Emotion and Cognition: Insights from Studies of the Human Amygdala. Annual Reviews of Psychology, v. 57, pp. 27-53, 2006.

PHILLIPS, M.L.; DREVETS, W.C.; RAUCH, S.L.; LANE, R. 2003 a. Neurobiology of Emotion Perception I: The Neural Basis of Normal Emotion Perception. Society of Biological Psychiatry, v. 54, pp. 504-514.

PHILLIPS, M.L.; DREVETS, W.C.; RAUCH, S.L.; LANE, R. 2003b. Neurobiology of Emotion Perception II: Implications for Major Psychiatric Disorders. Society of Biological Psychiatry, v. 54, pp. 515-528. 
RUSSELL, J.A. 2003. Core Affect and the Psychological Construction of Emotion. Psychological Review, v. 110, pp. 145-72.

SINGER, T.; KIEBEL, S.J.; WINSTON, J.S.; DOLAN, R.J.; FRITH, C.D. 2004. Brain Responses to the Acquired Moral Status of Faces. Neuron, v. 41, pp. 653-662.

SKINNER, B.F. 1953. Science and Human Behavior. New York: Macmillan.

SMITH, M.L.; COTTRELL, G.W.; GOSSELIN, F.; SCHYNS, P.G. 2005. Transmitting and Decoding Facial Expressions. Psychological Science, v. 16, n. 3, pp. 184-189.

SUSLOW, T.; OHRMANN, P.; BAUER, J.; RAUCH, A.V.; SCHWINDT, W.; AROLT, V.; HEINDEL, W.; KUGEL, H. 2006. Amygdala Activation During Masked Presentation of Emotional Faces Predicts Conscious Detection of Threat-related Faces. Brain and Cognition, v. 61, n. 3, pp. 243-248.

TAMIETTO, M.; GELDER, B. 2010. Neural Bases of the Nonconscious Perception of Emotional Signals. Nature Reviews Neuroscience, v. 11, pp. 697-709.

TODOROV, A.; OLSON, I.R. 2008. Robust Learning of Affective Trait Associations with Faces When the Hippocampus is Damaged, but Not When the Amygdala and Temporal Pole Are Damaged. Scan, v. 3, pp. 195-203.

VUILLEUMIER, P.; POURTOIS, G. 2007. Distributed and Interactive Brain Mechanisms During Emotion Face Perception: Evidence from Functional Neuroimaging. Neuropsychologia, v. 45, pp.174-194.

WHALEN, J.P.; SHIN, L.M.; MCINERNEY, S.C.; FISCHER, H.; WRIGHT, C.I.; RAUCH, S.L. 2001a. A Functional MRI Study of Human Amygdala Responses to Facial Expressions of Fear vs. Anger. Emotion, v. 1, pp. 70-83.

WHALEN, J.P.; CURRAN, T.; RAUCH, S.L. 2001b. Using Neuroimaging to Study Implicit Information Processing. In: 
DOUGHERTY, D.; RAUCH, S.L. Psychiatric neuroimaging research:

Contemporary Strategies. Washington, DC: American Psychiatric, pp. 73-100.

WHALEN, J.P.; DAVIS, M. 2001c. The Amygdala:Vigilance and Emotion. Molecular Psychiatry, v. 6, n. 1, pp. 13-34.

ZAMUNER, E. 2011. A Theory of Affect Perception. Mind \& Language, v. 26, n. 46, pp. 436-451. 